\title{
Embryonal tumor with abundant neuropil and true rosettes (ETANTR), ependymoblastoma, and medulloepithelioma share molecular similarity and comprise a single clinicopathological entity
}

\author{
Andrey Korshunov • Dominik Sturm • Marina Ryzhova • Volker Hovestadt • Marco Gessi • David T. W. Jones • \\ Marc Remke · Paul Northcott • Arie Perry • Daniel Picard · Marc Rosenblum • Manila Antonelli $\cdot$ Eleonora Aronica • \\ Ulrich Schüller • Martin Hasselblatt • Adelheid Woehrer • Olga Zheludkova • Ella Kumirova • Stephanie Puget • \\ Michael D. Taylor $\cdot$ Felice Giangaspero $\cdot$ V. Peter Collins $\cdot$ Andreas von Deimling $\cdot$ Peter Lichter $\cdot$ Annie Huang \\ Torsten Pietsch $\cdot$ Stefan M. Pfister $\cdot$ Marcel Kool
}

Received: 31 October 2013 / Revised: 29 November 2013 / Accepted: 7 December 2013 / Published online: 14 December 2013

(C) The Author(s) 2013. This article is published with open access at Springerlink.com

\begin{abstract}
Three histological variants are known within the family of embryonal rosette-forming neuroepithelial brain tumors. These include embryonal tumor with abundant neuropil and true rosettes (ETANTR), ependymoblastoma (EBL), and medulloepithelioma (MEPL). In this study, we performed a comprehensive clinical, pathological, and molecular analysis of 97 cases of these rare brain neoplasms, including genome-wide DNA methylation and copy number profiling of 41 tumors. We identified uniform molecular signatures in all tumors irrespective of
\end{abstract}

A. Korshunov · A. von Deimling

Clinical Cooperation Unit Neuropathology, German Cancer

Research Center (DKFZ), Heidelberg, Germany

A. Korshunov · A. von Deimling

Department of Neuropathology, Heidelberg University Hospital,

Heidelberg, Germany

D. Sturm · D. T. W. Jones · P. Northcott · S. M. Pfister ·

M. Kool ( $\square)$

Division of Pediatric Neurooncology, German Cancer Research Center (DKFZ), Im Neuenheimer Feld 280, 69120 Heidelberg,

Germany

e-mail: m.kool@dkfz.de

D. Sturm $\cdot$ S. M. Pfister

Department of Pediatric Hematology and Oncology, Heidelberg

University Hospital, Heidelberg, Germany

\section{Ryzhova}

Department of Neuropathology, NN Burdenko Neurosurgical

Institute, Moscow, Russia

V. Hovestadt $\cdot$ P. Lichter

Division of Molecular Genetics, German Cancer Research Center

(DKFZ), Heidelberg, Germany histological patterns, indicating that ETANTR, EBL, and MEPL comprise a single biological entity. As such, future WHO classification schemes should consider lumping these variants into a single diagnostic category, such as embryonal tumor with multilayered rosettes (ETMR). We recommend combined LIN28A immunohistochemistry and FISH analysis of the 19q13.42 locus for molecular diagnosis of this tumor category. Recognition of this distinct pediatric brain tumor entity based on the fact that the three histological variants are molecularly and clinically uniform

M. Gessi - T. Pietsch

Department of Neuropathology, University of Bonn, Bonn, Germany

M. Remke $\cdot$ D. Picard $\cdot$ M. D. Taylor · A. Huang Arthur and Sonia Labatt Brain Tumor Research Centre, Hospital for Sick Children, University of Toronto, Toronto, Canada

A. Perry

Departments of Pathology and Neurological Surgery, Brain Tumor Research Center, University of California, San Francisco, USA

M. Rosenblum

Department of Pathology, Memorial Sloan Kettering Cancer Center, New York, USA

M. Antonelli · F. Giangaspero

Department of Radiological, Oncological and Anatomic Pathology Sciences, Università Sapienza, Rome, Italy

\section{E. Aronica}

Department of Neuropathology, Academic Medical Center, Amsterdam, The Netherlands 
will help to distinguish ETMR from other embryonal CNS tumors and to better understand the biology of these highly aggressive and therapy-resistant pediatric CNS malignancies, possibly leading to alternate treatment strategies.

\section{Introduction}

According to the 2007 WHO classification of tumors of the central nervous system (CNS), CNS primitive neuroectodermal tumors (PNETs) can be further subdivided into CNS neuroblastoma/ganglioneuroblastoma, medulloepithelioma (MEPL), and ependymoblastoma (EBL) [18]. In addition, "embryonal tumor with abundant neuropil and true rosettes" (ETANTR) has been discussed as a possibly unique variant of CNS PNET [1, 2, 4, 6, 8, 10, 11, 19].

CNS neuroblastomas histologically and molecularly resemble subsets of medulloblastomas and peripheral neuroblastomas [18]. They are characterized by the presence of Homer Wright (neuroblastic) rosettes, foci of neurocytic and/or ganglion cell maturation, intense synaptophysin expression, and MYC/MYCN amplifications in almost $50 \%$ of cases $[3,18]$. On the other hand, ETANTR, EBL, and MEPL are rare neoplasms characterized by the presence of similar histological patterns, namely multilayered and pseudo-stratified rosette-forming structures of variable shape and size. Both EBL and ETANTR include the socalled "ependymoblastic rosettes" harboring well-formed central round or slit-like lumina in the absence of an outer membrane $[4,6,11,12,14,18]$. MEPL is histologically

U. Schüller

Center of Neuropathology, Ludwig-Maximilians University, Munich, Germany

M. Hasselblatt

Institute of Neuropathology, University Hospital Münster,

Münster, Germany

A. Woehrer

Institute of Neurology, Medical University of Vienna, Vienna, Austria

O. Zheludkova $\cdot$ E. Kumirova

Department of Pediatric Neurooncology, Dmitry Rogachev

Federal Research Center of Pediatric Hematology, Oncology and Immunology, Moscow, Russia

S. Puget

Department of Pediatric Neurosurgery, Necker Hospital,

Université Paris Descartes, Sorbonne Paris Cité, Paris, France

F. Giangaspero

IRCCS Neuromed, Pozzilli, Italy

V. Peter Collins

Department of Pathology, University of Cambridge, Cambridge, UK characterized by papillary and tubular structures surrounded by an external limiting membrane, reminiscent of the developing neural tube $[4,18]$. These structures are sometimes also referred to as "medulloepithelial" rosettes. Moreover, some MEPL have also been reported to display ependymoblastic rosettes [18]. These three variants of embryonal CNS tumors show a clinically uniform behavior, in that they predominantly affect infants under the age of 4 years and are associated with a highly aggressive course with reported survival times up to 24-36 months, but typically averaging 12 months $[1,5,9,11,15,23]$.

Applying FISH analysis, we previously found amplifications at 19q13.42 involving the C19MC cluster in $93 \%$ of tumors diagnosed either as ETANTR, EBL, or MEPL with ETANTR features, but not in any other pediatric brain tumors [15]. These results demonstrate that this genetic aberration is highly sensitive and specific to embryonal CNS tumors with multilayered rosettes irrespective of other features and that these subtypes are highly interrelated. Recently, Paulus and Kleihues therefore proposed to use the term "embryonal tumor with multilayered rosettes" (ETMR) as a general name for these tumors, a new entity, in part defined by the C19MC amplification itself [22].

To further test whether the three histological variants of ETMR represent a single entity, we performed clinicopathological and molecular analyses in 97 ETMR samples initially designated as ETANTR, EBL, or MEPL.

\section{Materials and methods}

Ninety-seven diagnostic specimens diagnosed histopathologically as either ETANTR, EBL, or MEPL were received for this study from various sources around the globe and collected during the last 5 years. Among these sources were Burdenko Neurosurgical Institute, Moscow, Russia; University of Bonn, Germany; Ludwig-Maximilians University, Munich, Germany; University of Münster, Germany; University of Tübingen, Germany; Università Sapienza, Rome, Italy; Necker Hospital, Paris, France; Academic Medical Center, Amsterdam, the Netherlands; University of Cambridge, Cambridge, UK; Institute of Neurology, Vienna, Austria; Hospital for Sick Children, Toronto, Canada; Memorial Sloan Kettering Cancer Center, New York, USA; and University of California, San Francisco, USA. A subset of these cases was previously published $[15,16]$.

All cases were routinely formalin fixed and paraffin embedded. For diagnostic purposes, routine histopathological examination and immunohistochemical (IHC) analyses were performed in the different institutions participating in this study. Further centralized evaluation of all H\&E slides was performed in the Heidelberg University Department of Neuropathology. In all 97 cases, IHC analysis applying 
a LIN28A polyclonal antibody and FISH analysis for the $19 \mathrm{q} 13.42$ locus were performed as previously described $[15,16]$.

For samples for which sufficient DNA was available $(n=41)$, we analyzed copy number aberrations (CNAs) using data generated with Illumina Human Methylation 450 k BeadChip arrays as described previously [13, 26]. For the detection of amplifications, chromosomal gains and losses, automatic scoring was verified by manual assessment of the respective loci for each individual profile as previously described [26].

To evaluate the molecular specificity of potential ETMR subtypes, we performed comparative cluster analysis of $450 \mathrm{k}$ profiles generated for 41 ETMR together with 110 other primary pediatric brain tumors including pilocytic astrocytoma (PA; $n=10$ ), ependymoma (EPN; $n=10$ ), glioblastoma grade IV (GBM; $n=40)$, atypical teratoid rhabdoid tumor (AT/RT; $n=10)$, and medulloblastoma (MB; $n=40$ ). Eight normal cerebellum (CBM) samples were also included. The following criteria were applied to filter the data: removal of probes targeting the $\mathrm{X}$ and $\mathrm{Y}$ chromosomes $(n=11,551)$, removal of probes containing a single-nucleotide polymorphism (dbSNP132 Common) within five base pairs of and including the targeted CpG-site $(n=24,536)$, and probes not mapping uniquely to the human reference genome (hg19) allowing for one mismatch $(n=9,993)$. In total, 438,370 probes were kept for analysis. For unsupervised hierarchical clustering of 41 ETMR samples, we selected the 4,756 most variably methylated probes across the dataset (s.d. $>0.25$ ). Samples were clustered using 1-Pearson correlation coefficient as the distance measure and average linkage (x-axis). Methylation probes were reordered by hierarchical clustering using euclidean distance and average linkage (y-axis). The heatmap illustration of 41 ETMR samples and 118 other pediatric brain tumor and control samples was generated by separately determining the 2,500 most variably methylated probes between the medulloblastoma subgroups, the K27-, G34-, IDH-, and wt (not H3.3 or IDH mutated) GBM subgroups, the non-ETMR tumor samples, and across the whole dataset. Probes were only used once $(n=6,540)$. Methylation probes were reordered by hierarchical clustering using euclidean distance and average linkage (y-axis).

\section{Results}

Pathological examination of the ETMR cohort

According to published histopathological criteria, the 97 ETMR cases studied were diagnosed as ETANTR (55 cases), EBL (34 cases), or MEPL (eight cases) after central review. ETANTR was defined according to the criteria previously described by Eberhart et al. [6]. These tumors showed a biphasic pattern featuring highly cellular clusters of small cells with round or polygonal nuclei and scanty cytoplasm admixed with large fibrillar and paucicellular neuropil-like areas, infrequently containing neoplastic neurons. Among the clusters and aggregates of small cells, numerous true multilayered ependymoblastic rosettes were identified (Fig. 1a). In some cases, these rosettes were observed abruptly in the neuropil areas and neoplastic neurons were found between the cells composing layers of the rosettes. EBL and MEPL were diagnosed according to current WHO classification criteria [18]. EBL was identified as a tumor with the exclusive presence of nests and clusters of poorly differentiated cells forming true multilayered ependymoblastic rosettes but lacking a neuropil-like matrix (Fig. 1d). These rosettes were intermixed with small to medium-sized primitive cells having a high nucleus/cytoplasm ratio and variably developed fibrillary processes. MEPL was characterized by the presence of papillary, tubular, and/or trabecular arrangements of neoplastic pseudostratified epithelium with an outer membrane resembling the primitive neural tube (Fig. 1g). In zones distinct from tubular structures, large areas of poorly differentiated cells including collections of true multilayered ependymoblastic rosettes were found in all eight cases studied.

Recently, we have shown that expression of LIN28A is a highly specific and sensitive marker for pathological verification of ETMR [16, 23]. In the present series, strong and diffuse LIN28A cytoplasmic immunostaining was found in all 97 tumors studied irrespective of their histopathological appearance mentioned above (Fig. 1c, f, i). LIN28A positivity was found to be more prominent and intense in multilayered rosettes and poorly differentiated small-cell tumor areas of ETANTR/EBL, and in papillary and tubular structures of MEPL.

Pathological analysis of recurrent ETMR samples

We were able to perform histological and molecular analysis of 14 samples obtained from local recurrences of ETMR: 11 were initially diagnosed as ETANTR, two as EBL, and one as MEPL. In addition, three samples from extracranial metastases of ETANTR (one in cranial soft tissue and two in the peritoneal cavity) were analyzed.

Upon secondary surgery at the time of relapse, histopathology in all 11 ETANTR samples showed a loss of neuropil-like foci. The secondary biopsy specimens obtained from nine ETANTRs disclosed extended collections of multilayered rosettes with various size and shape reflecting a histological pattern compatible with EBL (Fig. 2a, b). The other two samples showed prominent papillary and tubular structures, closely resembling MEPL (Fig. 2c, d). The extracranial metastasis of one ETANTR was predominantly 

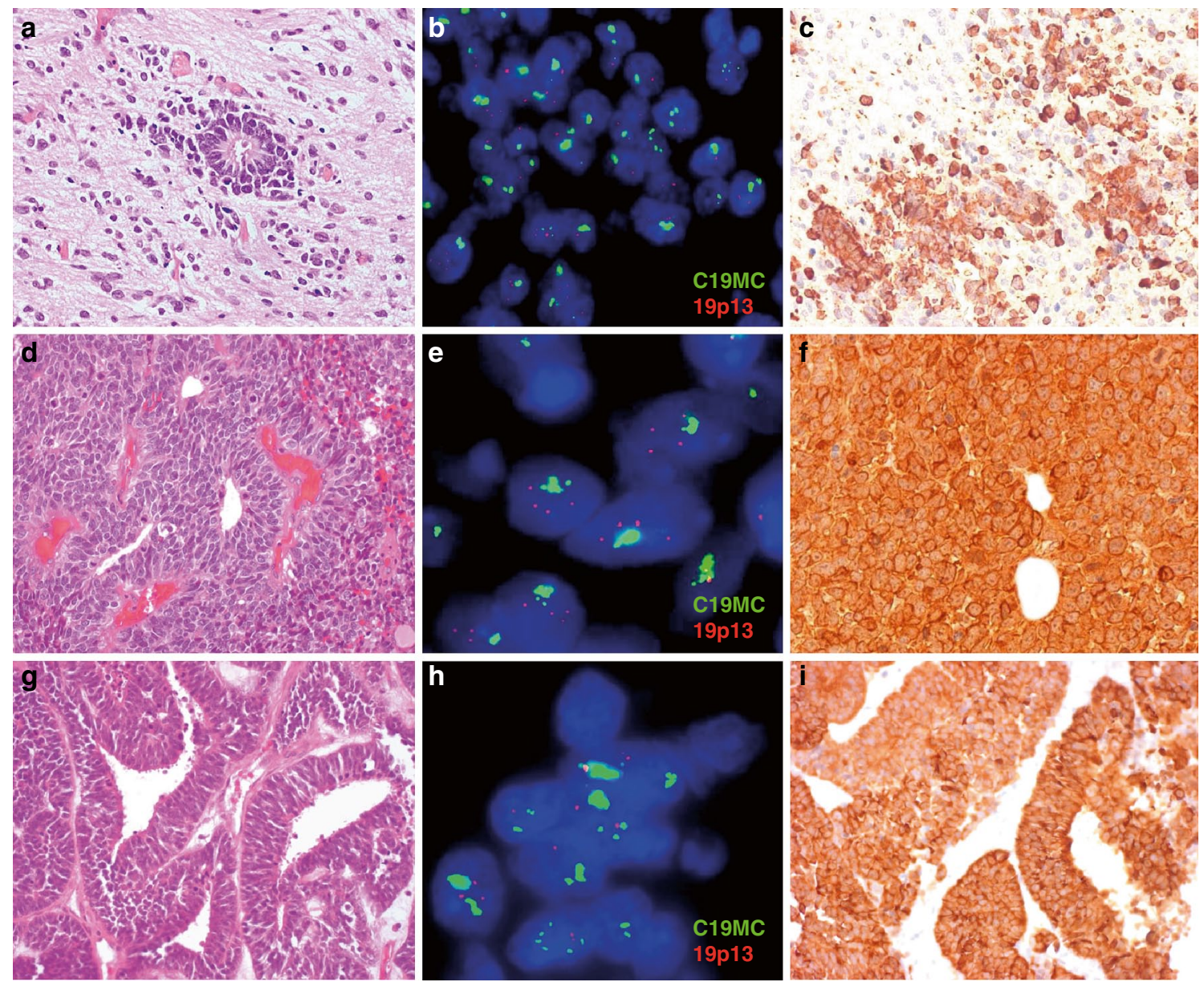

Fig. 1 Microscopical appearance (a, d, g), FISH analysis of the 19q13.42 locus (b, e, h), LIN28A immunohistochemistry (c, f, i) of ETANTR $(\mathbf{a}-\mathbf{c})$, EBL $(\mathbf{d}-\mathbf{f})$ and MEPL $(\mathbf{g}-\mathbf{i})$. Amplification of $19 q 13.42$ (b, e, h) and LIN28A immunoexpression (c, f, i) was detected in all three histological ETMR subtypes. For the FISH analysis the C19MC 19q13.42 probe (green signals) and a reference $19 \mathrm{p} 13$ probe were used (red signals)

mean age for the three histological variants of ETMR did not differ significantly. Most tumors (64 cases; $70 \%$ ) were located supratentorially, with almost half of these $(n=30)$ found in the fronto-parietal region. Infratentorial location was less frequent ( 27 cases; $30 \%$ ) affecting either the cerebellum $(n=10)$ or brain-stem $(n=17)$. Exact information about tumor location was not available for six patients. Supra- and infratentorial location within the three ETMR groups did not differ significantly (Table 1). Data on metastatic stage at tumor diagnosis were available for only 32 patients. Most presented with M0 disease $(26 / 32,80 \%)$, two with M2 stage, and four with M3 stage.

Details of patient treatment were known for 36 patients (18 ETANTR; 14 EBL, and 4 MEPL). Sixteen patients had undergone gross total tumor resection, while for the other 20 children only subtotal tumor removal could be achieved. Only three patients received postoperative cranio-spinal irradiation, whereas all 36 patients were treated with chemotherapy based on the HIT-SKK2000 
Fig. 2 Two examples of primary ETANTR $(\mathbf{a}, \mathbf{c})$ with further tumor transformation in either EBL (b) or MEPL

(d) histology as it has been identified during analysis of the recurrence samples

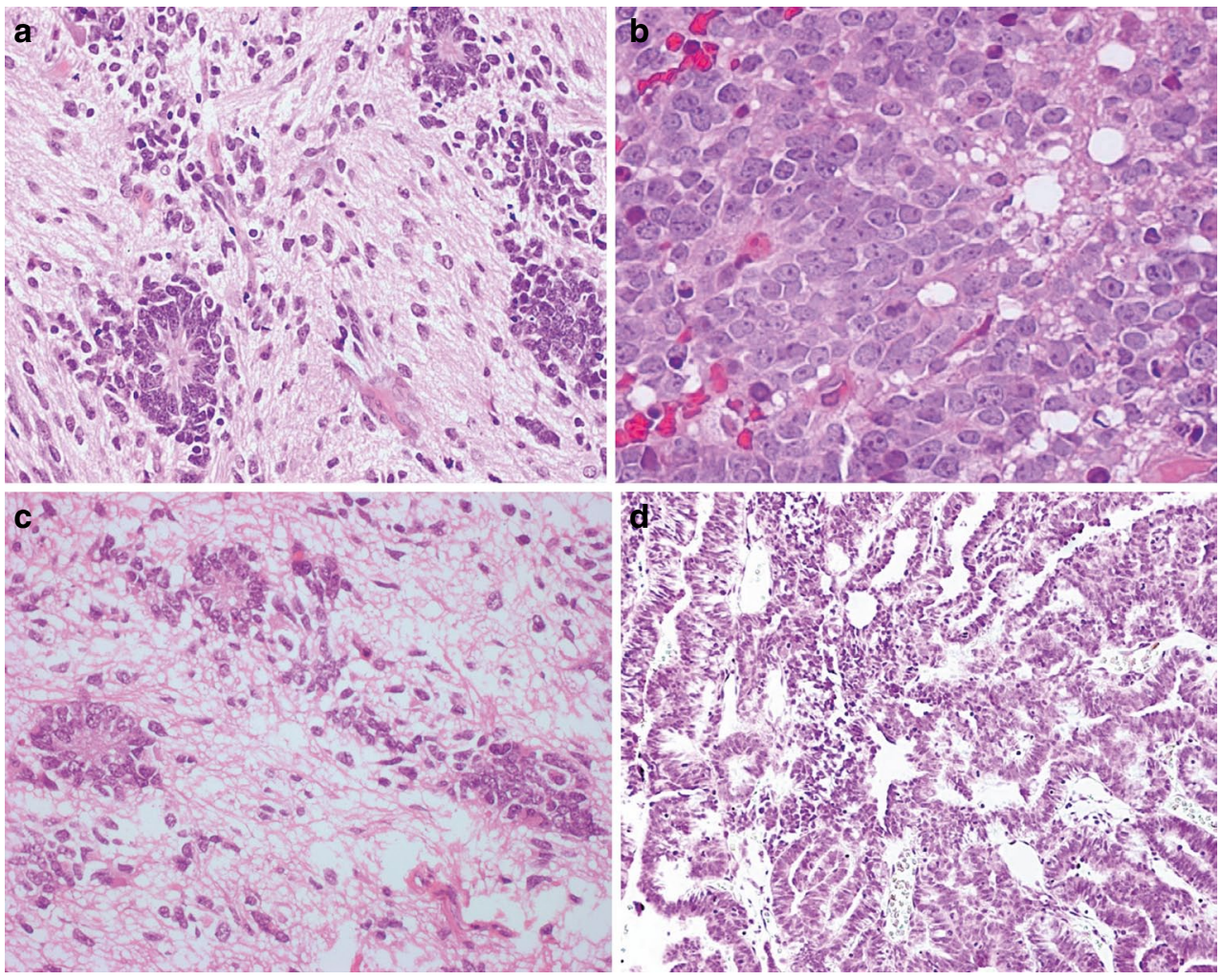

Table 1 Patient characteristics of 97 ETMR cases

\begin{tabular}{llll}
\hline Variable & $\begin{array}{l}\text { ETANTR } \\
(n=55)\end{array}$ & $\begin{array}{l}\text { EBL } \\
(n=34)\end{array}$ & $\begin{array}{l}\text { MEPL } \\
(n=8)\end{array}$ \\
\hline Age (years) & & & \\
$\quad$ Median & 2.5 & 2.6 & 2.2 \\
$\quad$ Range & $1-5$ & $0.5-6$ & $1-3$ \\
Gender & & & \\
$\quad$ Male & 29 & 15 & 3 \\
Female & 26 & 19 & 5 \\
Tumor location & & & \\
$\quad$ Supratentorial & 37 & 21 & 6 \\
$\quad$ Infratentorial & 14 & 11 & 2 \\
Events & & & \\
Recurrence & $29 / 32$ & $16 / 17$ & $5 / 6$ \\
$\quad$ Death & $26 / 32$ & $14 / 17$ & $5 / 6$ \\
Survival & & & \\
$\quad$ Median PFS (months) & 9.3 & 7.1 & 7.3 \\
$\quad$ Median OS (months) & 13.1 & 11.4 & 10.8 \\
\hline
\end{tabular}

protocol [9]. Follow-up data were available for 55 patients demonstrating that 50 tumors recurred during follow-up with a median progression-free survival (PFS) of 8 months, and $84 \%(46 / 55)$ of patients died within 3 years after their initial diagnosis. Median overall survival (OS) was 12.3 months and did not differ significantly between the three histological variants of ETMR

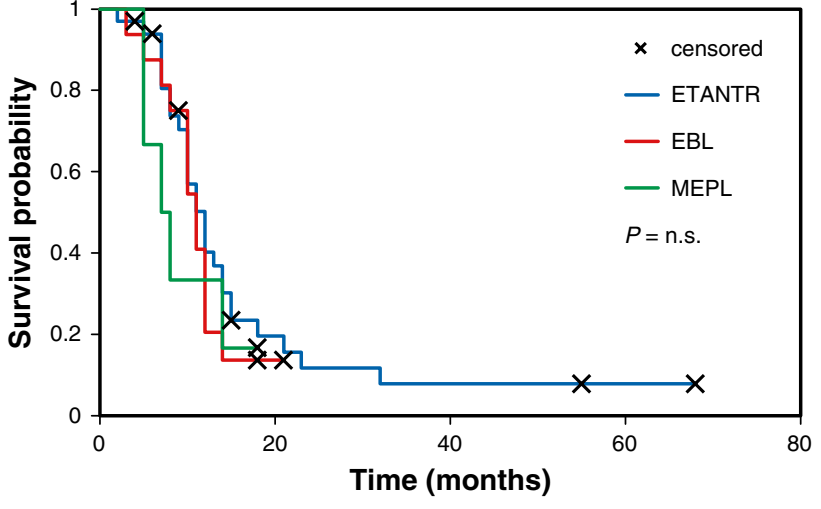

Fig. 3 Overall survival curves generated for ETANTR (32 cases, blue), EBL (17 cases, red), and MEPL (6 cases, green). No differences in survival time were found (log-rank, $p=0.63$ )

(log-rank; $p=0.63$, Fig. 3). Only two patients with an initial histological diagnosis of ETANTR are still alive more than 4 years after the first intervention (57 and 68 months, respectively).

Patterns of disease progression were highly variable. Most of the patients experienced local tumor regrowth as a first recurrence pattern, whereas a smaller number developed widespread leptomeningeal metastatic dissemination, very often after intervention on the recurrent lesion. Four patients additionally showed systemic metastases outside of the CNS in the cranial soft tissue, as well as pleural and peritoneal cavities. 
a

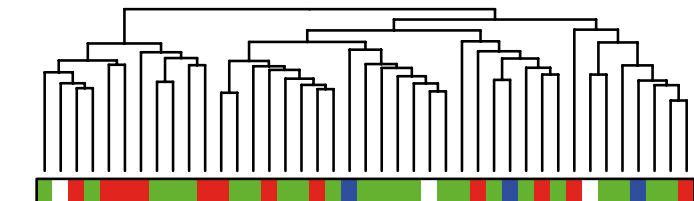

$$
\begin{array}{|c} 
\\
\end{array}
$$
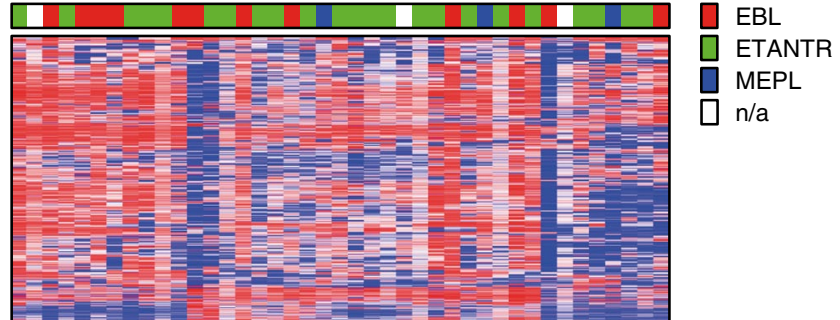

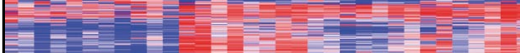

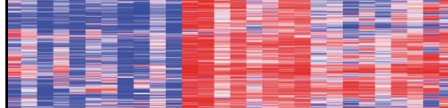

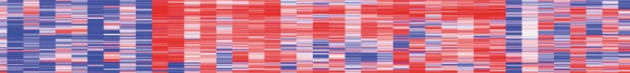

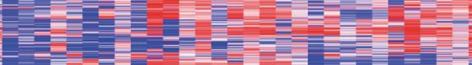

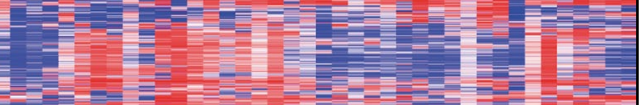

$=$

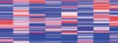

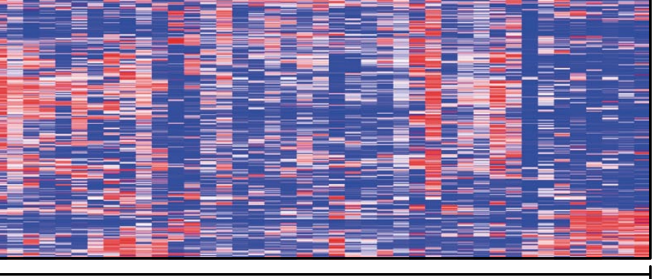

41 samples

b

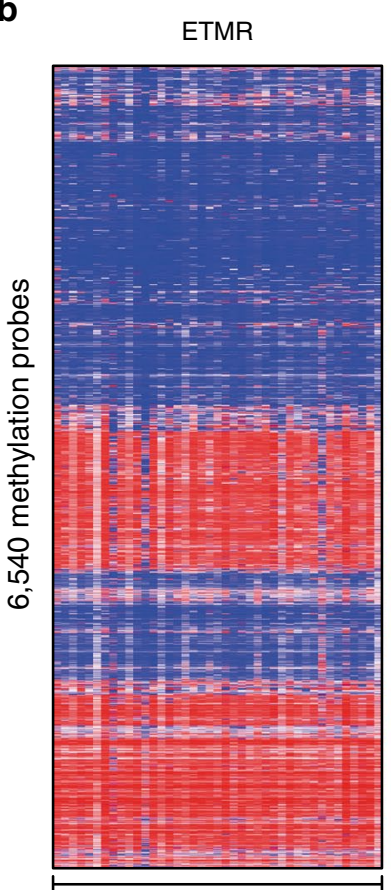

41 samples
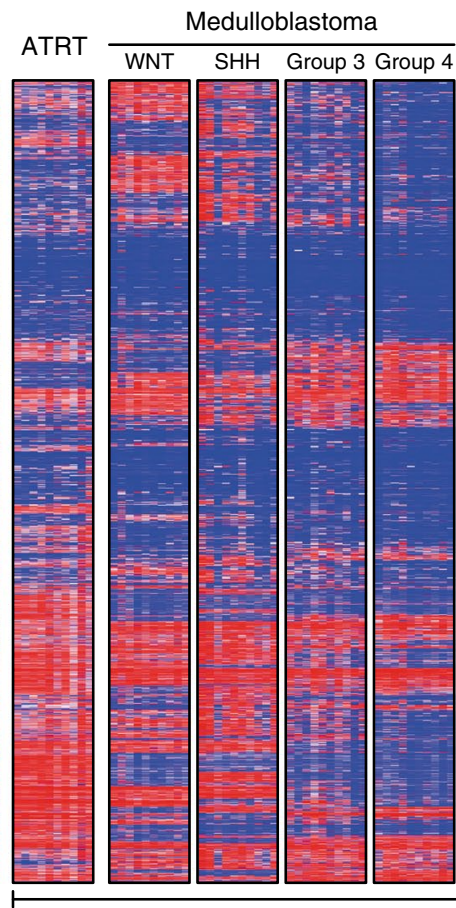

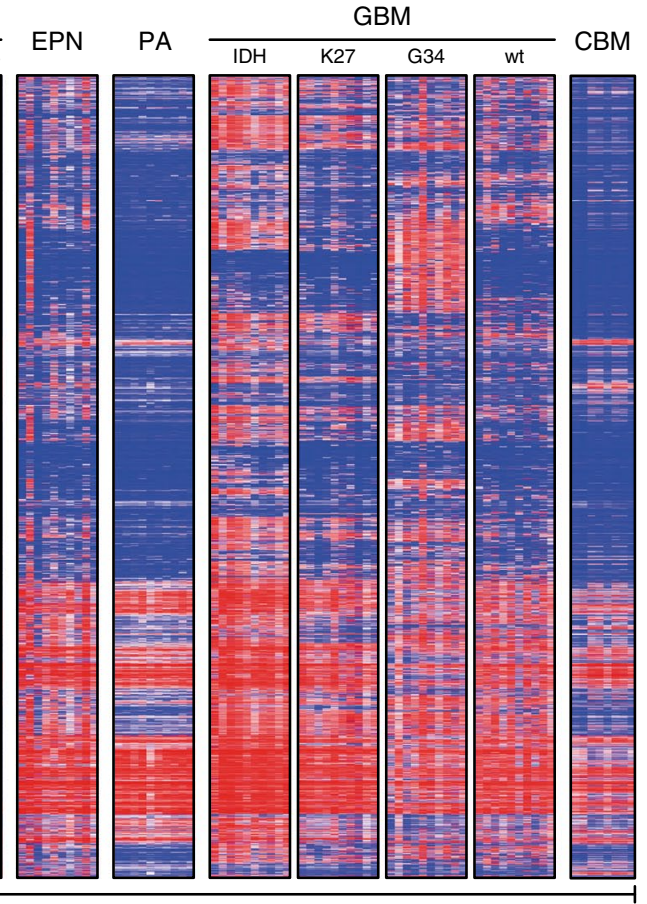

118 samples
Fig. 4 Cluster analyses of DNA methylation profiles of ETMR alone and compared to various other pediatric brain tumors and normal cerebellum. a Unsupervised cluster analysis of ETMR samples only shows that DNA methylation profiles of the histological variants beta-values

0.51

EBL

MEPL 
Table 2 Copy number aberrations in 41 ETMR cases

\begin{tabular}{|c|c|c|c|c|c|c|c|c|}
\hline$N$ & Age (years) & Gender & Location & Histology & Amplification & Gains & Losses & Outcome \\
\hline 1 & 2 & $\mathrm{~F}$ & Supra & ETANTR & $19 \mathrm{ql} 3.42$ & 2 & No & $\operatorname{DOD}(21 \mathrm{~m})$ \\
\hline 2 & 2 & M & Supra & ETANTR & $19 q 13.42$ & 7 & $6 \mathrm{q}$ & $\operatorname{NED}(57 \mathrm{~m})$ \\
\hline 3 & 3 & $\mathrm{~F}$ & Supra & ETANTR & $19 q 13.42$ & 2 & $19 q$ & DOD $(18 \mathrm{~m})$ \\
\hline 4 & 2 & $\mathrm{M}$ & Infra & ETANTR & $19 \mathrm{ql} 3.42$ & 2 & No & DOD $(10 \mathrm{~m})$ \\
\hline 5 & 1 & $\mathrm{~F}$ & Infra & ETANTR & No & lq, $19 p$ & No & DOD (32 m) \\
\hline 6 & 2 & $\mathrm{M}$ & Supra & ETANTR & $19 \mathrm{ql} 3.42$ & $2,14,17,20$ & No & D0D (12 m) \\
\hline 7 & 3 & $\mathrm{~F}$ & Supra & ETANTR & $19 \mathrm{ql} 3.42$ & 2 & No & DOD $(15 \mathrm{~m})$ \\
\hline 8 & 2 & $\mathrm{M}$ & Supra & ETANTR & $19 \mathrm{ql} 3.42$ & 2 & No & DOD $(10 \mathrm{~m})$ \\
\hline 9 & 2 & $\mathrm{~F}$ & Infra & ETANTR & $19 \mathrm{ql} 3.42$ & $7,11 q$ & $6 \mathrm{q}, 9,12 \mathrm{q}, 16$ & DOD (23 m) \\
\hline 10 & 3 & $\mathrm{~F}$ & Supra & ETANTR & $19 \mathrm{ql} 3.42$ & $2,7,11$ & $6 \mathrm{q}, 19 \mathrm{q}$ & DOD $(10 \mathrm{~m})$ \\
\hline 11 & 3 & M & Infra & ETANTR & $19 q 13.42$ & $2,4,7,1 \mathrm{lq}$ & $1 p, 19 q$ & DOD $(10 \mathrm{~m})$ \\
\hline 12 & 2 & $\mathrm{~F}$ & Supra & ETANTR & $19 q 13.42$ & $2,21 \mathrm{q}$ & No & $\operatorname{DOD}(12 \mathrm{~m})$ \\
\hline 13 & 3 & M & Supra & ETANTR & $19 \mathrm{ql} 3.42$ & 2,16 & No & DOD $(11 \mathrm{~m})$ \\
\hline 14 & 2 & $\mathrm{~F}$ & Supra & ETANTR & $19 \mathrm{q} 13.42$ & No & $6 \mathrm{q}$ & $\operatorname{DOD}(12 \mathrm{~m})$ \\
\hline 15 & 3 & M & Supra & ETANTR & $19 \mathrm{ql} 3.42$ & 2 & No & POD (6 m) \\
\hline 16 & 2 & $\mathrm{~F}$ & Supra & ETANTR & $19 q 13.42$ & 2 & No & NA \\
\hline 17 & 3 & M & Supra & ETANTR & $19 q 13.42$ & 2 & No & DOD (14 m) \\
\hline 18 & 3 & $\mathrm{~F}$ & Supra & ETANTR & $19 q 13.42$ & No & $7 \mathrm{q}$ & NA \\
\hline 19 & 2 & M & Supra & ETANTR & $19 \mathrm{ql} 3.42$ & $\mathrm{lq}, 2,4,7 \mathrm{q}, 12 \mathrm{q}, 13 \mathrm{q}, 21 \mathrm{q}$ & $8 \mathrm{q}, 10 \mathrm{q}$ & POD (4 m) \\
\hline 20 & 5 & M & Infra & ETANTR & $19 \mathrm{ql} 3.42$ & 2,11 & No & DOD (9 m) \\
\hline 21 & 2 & M & Supra & ETANTR & $19 \mathrm{ql} 3.42$ & lq, $2,6 \mathrm{p}, 7,1 \mathrm{lq}, 21 \mathrm{q}$ & lp, lip, 18p, 22q & DOD (7 m) \\
\hline 22 & 3 & $\mathrm{~F}$ & Supra & ETANTR & $19 q 13.42$ & $\mathrm{lq}, 2,4,7,8,11,16,17,20,21 \mathrm{q}$ & No & NED (68 m) \\
\hline 23 & 2 & M & Supra & ETANTR & $19 \mathrm{q} 13.42$ & $2,15 q$ & No & DOD (9 m) \\
\hline 24 & 2 & $\mathrm{~F}$ & Supra & EBL & $19 \mathrm{ql} 3.42$ & $2,3,4,7,8,13 q$ & No & $\operatorname{DOD}(10 \mathrm{~m})$ \\
\hline 25 & 2 & $\mathrm{~F}$ & Supra & EBL & $19 q 13.42$ & llq & lp, 19q, 22q & $\operatorname{DOD}(12 \mathrm{~m})$ \\
\hline 26 & 3 & M & Supra & EBL & $19 \mathrm{q} 13.42$ & lq, 7 & $6 q, 19 q$ & $\operatorname{DOD}(10 \mathrm{~m})$ \\
\hline 27 & 2 & M & Supra & EBL & $19 \mathrm{q} 13.42$ & $6 \mathrm{p}, 7$ & No & $\operatorname{DOD}(10 \mathrm{~m})$ \\
\hline 28 & 2 & $\mathrm{~F}$ & Supra & EBL & $19 \mathrm{q} 13.42$ & lq, $2,3 q, 4$ & No & $\operatorname{DOD}(11 \mathrm{~m})$ \\
\hline 29 & 2 & M & Supra & EBL & $19 \mathrm{q} 13.42$ & 2 & $6 \mathrm{q}, 17 \mathrm{p}$ & DOD (6 m) \\
\hline 30 & 2 & M & Infra & EBL & No & $\mathrm{lq}, 2,17 \mathrm{q}$ & No & DOD $(9 \mathrm{~m})$ \\
\hline 31 & 3 & $\mathrm{~F}$ & Supra & EBL & $19 q 13.42$ & 2 & No & NED (6 m) \\
\hline 32 & 3 & $\mathrm{~F}$ & Infra & EBL & $19 q 13.42$ & $2,19,20,21 q$ & No & NA \\
\hline 33 & 2 & $\mathrm{~F}$ & Supra & EBL & $19 q 13.42$ & $2,5 \mathrm{q}, 7,1 \mathrm{qq}, 15 \mathrm{q}, 21 \mathrm{q}$ & $22 q$ & POD (11) \\
\hline 34 & 3 & M & Supra & EBL & $19 q 13.42$ & $\mathrm{lq}, 2,6 \mathrm{p}, 17,20 \mathrm{q}$ & $6 \mathrm{q}, 14 \mathrm{q}, 19 \mathrm{q}$ & POD (21 m) \\
\hline 35 & 2 & $\mathrm{~F}$ & Supra & EBL & $19 q 13.42$ & No & $19 \mathrm{q}$ & NA \\
\hline 36 & 3 & M & Supra & MEPL & $19 \mathrm{q} 13.42$ & $2,5 \mathrm{p}, 11 \mathrm{q}, 17 \mathrm{q}, 20 \mathrm{q}$ & $1 p, 6 q, 12 p, 19 q$ & DOD $(6 \mathrm{~m})$ \\
\hline 37 & 2 & M & Supra & MEPL & $19 q 13.42$ & $2,17,19$ & No & $\operatorname{DOD}(5 \mathrm{~m})$ \\
\hline 38 & 1 & $\mathrm{~F}$ & Supra & MEPL & $19 q 13.42$ & 2 & No & $\operatorname{DOD}(7 \mathrm{~m})$ \\
\hline 39 & NA & NA & NA & NA & $19 q 13.42$ & 2 & No & NA \\
\hline 40 & NA & NA & NA & NA & $19 q 13.42$ & 2 & No & NA \\
\hline 41 & NA & NA & NA & NA & 19q13.42 & $2,7 q, 8$ & No & NA \\
\hline
\end{tabular}

ETANTR embryonal tumor with abundant neuropil and true rosettes, $E B L$ ependymoblastoma, $M E P L$ medulloepithelioma, $D O D$ died of disease, $P O D$ alive, progression of disease, $N E D$ alive, no evidence of disease, $N A$ not available

Cytogenetic analysis of 19q13.42 locus in ETMR

All 97 tumor samples were analyzed by FISH for amplification of the 19q13.42 locus. A high-level focal amplification of this locus (present in $40-80 \%$ of tumor nuclei) was detected in 93 samples (96\%) (Fig. 1b, e, h). The four remaining tumors (two diagnosed as ETANTR and two as EBL) displayed polysomy 19, i.e., a low-level 
a

ETANTR22 (ETANTR)

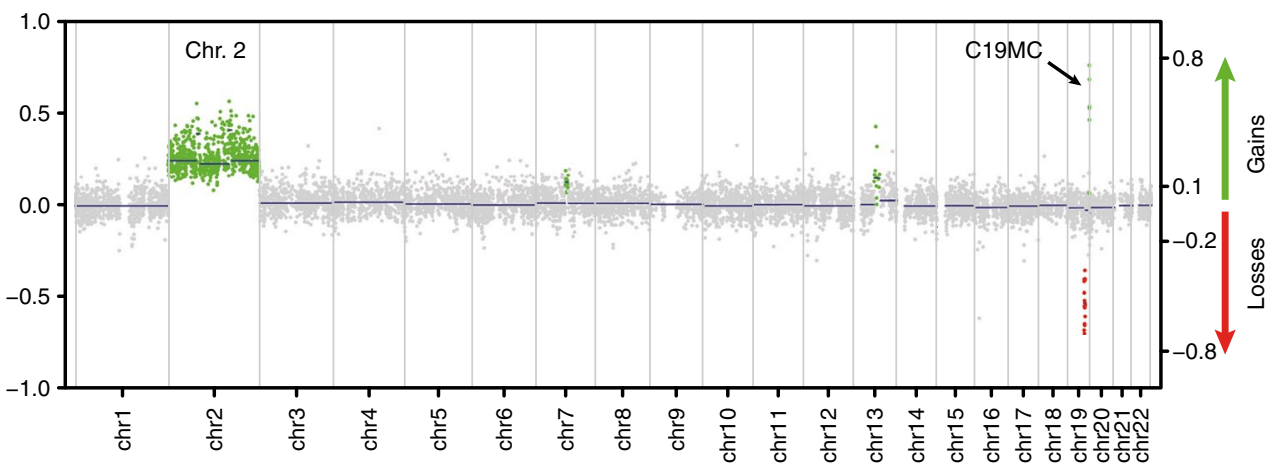

b

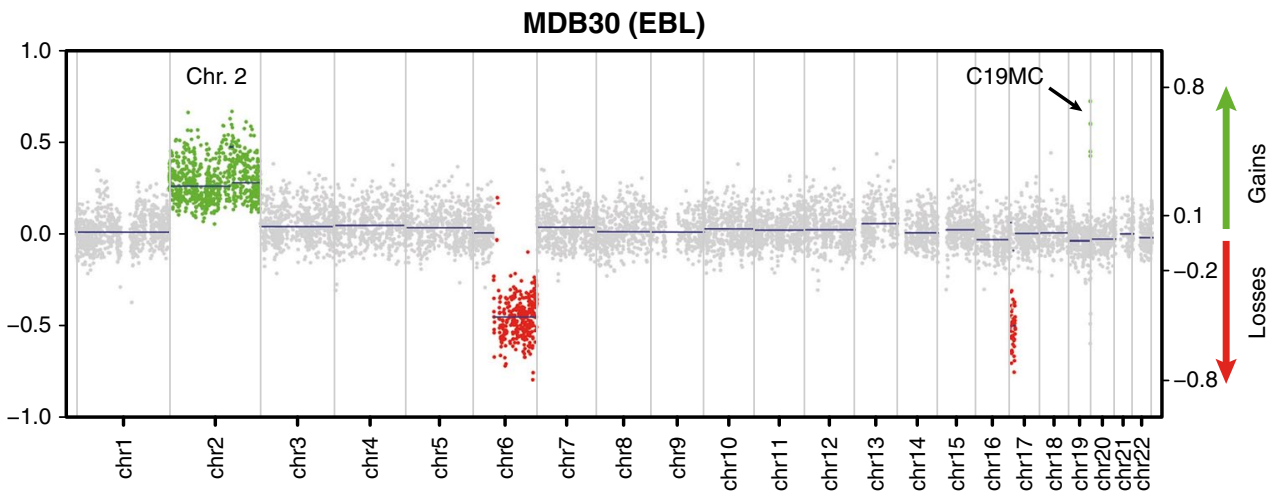

C
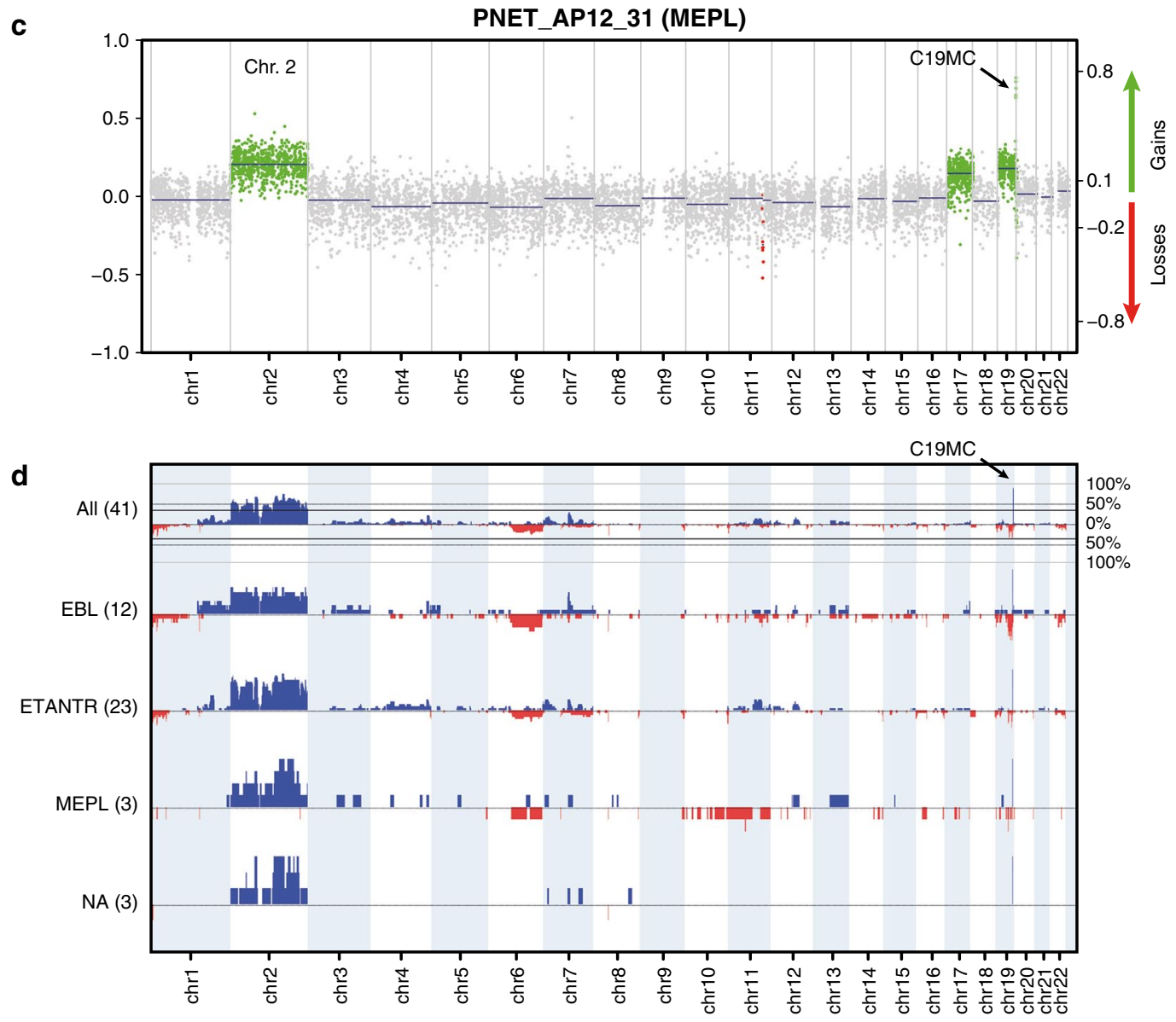
४Fig. 5 Copy number plots generated from $450 \mathrm{k}$ methylation data. Amplifications and gains are indicated in green, losses in red. a Example of an ETANTR showing amplification 19q13.42, gain of 2 and loss of 19q13.3. b Example of an EBL showing amplification 19q13.42, gain of 2, and losses of 6q and 17p. c Example of a MEPL showing amplification 19q13.42, trisomy of 2, 17 and 19. d Summarizing profiles for all 41 cases analyzed

gain of both the target locus and the reference locus, compatible with an aberration affecting large parts of the chromosome or with an overall state of polyploidy. FISH analysis of the 14 recurrent tumors showed that the $19 \mathrm{q} 13.42$ amplification was retained in all samples. Moreover, the number of nuclei with amplification was significantly higher in secondary lesions (up to $100 \%$ of nuclei) in comparison to their matched primary tumors [15].

DNA copy number analysis and methylation profiling of ETMR

Next, we analyzed the genome-wide DNA methylation profiles of 41 ETMR samples using the Illumina $450 \mathrm{k}$ DNA methylation arrays. As shown previously for glioblastoma and medulloblastoma [13, 26], DNA methylation profiling provides an excellent tool for the molecular sub-classification of distinct tumor entities. Unsupervised clustering analysis of the methylation data of the 41 ETMR samples did not reveal subgrouping according to ETMR histological subtypes (Fig. 4a). However, comparison to a large cohort of other pediatric brain tumors $(n=110)$ revealed that ETMRs are clearly distinct from other CNS tumors (Fig. 4b). In addition, data generated from these arrays can be used to detect CNAs in individual tumor samples. All CNAs detected from the methylation arrays for these 23 ETANTR, 12 EBL, 3 MEPL, and 3 additional histologically unidentified cases are outlined in Table 2. Amplification of the 19q13.42 locus was confirmed for 39/41 (95\%) primary tumors examined. Only one ETANTR and one EBL showed no amplification confirming the FISH analyses in these two samples. No other genomic amplifications were detected in this series of primary ETMR. Other recurrent low-level CNAs in these tumors included gain of chromosome 2 in 31 cases ( $76 \%$ ), gain of $7 \mathrm{q}(12 / 41$, $29 \%)$, gain of $11 \mathrm{q}(9 / 41,22 \%)$, gain of $1 \mathrm{q}(8 / 41,20 \%)$, and loss of $6 \mathrm{q}$ in eight cases $(20 \%)$. In eight cases, we additionally identified a focal genomic loss at 19q13.213.3 , i.e., centromeric to the $C 19 M C$ amplified region, suggesting complex intra-chromosomal rearrangements on the 19q13 locus in a subset of ETMR. No significant differences in the frequency of any of these CNAs were detected between the three histological ETMR variants (Fig. 5).

\section{Discussion}

Currently, the verification of a distinct nosologic position for various human malignancies is complemented (or sometimes defined) by a comprehensive molecular workup [23, 26]. A number of refinements have recently been introduced into the current histological classification of pediatric CNS tumors. For example, the routine application of molecular diagnostics distinguishes AT/RTs from other PNETs [18] and current studies strongly suggest incorporating four molecular medulloblastoma subgroups into the classification as separate tumor entities [20]. These molecular data will help to further subdivide existing tumor entities by identifying disease variants with diverse clinical outcomes, distinct biology and clues regarding cell of origin. In contrast, molecular analyses of a representative cohort of ETANTR, EBL, and MEPL, three rare variants of embryonal CNS neoplasms, strongly suggests their integration into one single tumor entity called ETMR. All tumors were positive for LIN28A, a marker highly specific for ETMRs, and almost all cases displayed amplification of the C19MC miRNA cluster at $19 \mathrm{q} 13.42$, as well as frequent trisomy 2. Furthermore, no significant differences in other CNAs were observed between these three histological variants and their DNA methylation patterns were highly concordant.

Morphologically, ETMR manifests uniformly with the presence of multilayered true rosettes: "ependymoblastic" and/or "medulloepithelial", with variable shape and size. As already noted, it may frequently be difficult to distinguish between EBL and MEPL [18]. Diagnostic differences between these tumor categories are descriptive and conceptual because they are, in general, based only on the absence of an outer collagen IV-positive membrane and apical cytoplasmic blebs in EBL structures. Moreover, similar clinical parameters and a highly aggressive course of disease for all ETMR histological variants (resistance to treatment, inevitable tumor recurrence and rapid death) also support our suggestion of commonality $[1,8,9,11,15,16,19]$.

Previously, molecular analysis of various ETMR subtypes has been hampered by limited cohort sizes and to date, only a few chromosomal imbalances were detected by conventional CGH analysis [7, 25]. Recently, we described a focal unique amplicon at $19 \mathrm{q} 13.42$ spanning $0.89 \mathrm{Mb}$ and covering the $C 19 M C$ genomic locus, the largest known cluster of human microRNA-coding genes [24]. Further, the $C 19 M C$ locus was found to be amplified in $93 \%$ of ETMR diagnosed previously on the basis of their characteristic morphology [15], and these findings have been confirmed by others $[5,17,21,23,27,28]$. Thus, C19MC amplification is a highly specific genetic ETMR hallmark, similar to loss of the SMARCB1 locus in AT/RT or t $(11 ; 22)$ in Ewing sarcoma [18]. This suggests that the C19MC 
amplification could serve as a "driver" oncogenic event in ETMR. Comprehensive analysis of CNAs in our ETMR cohort revealed few other recurrent chromosomal gains and losses, and no subtle cytogenetic differences between the tumors with various histological features could be defined.

Common molecular signatures between the three histological variants of ETMR suggest that they may share a common origin, such as a primitive cell population in the subependymal region, with further evolution into a wide range of morphological appearances and mimics. In support of this suggestion, analysis of the 11 recurrent ETANTR samples revealed its frequent histological evolution into either EBL or MEPL phenotypes, while at the same time the molecular genetic make-up did not change between the initial and advanced stages of disease. Such stepwise morphologic transformations in the "classic" ETANTR appearance due to disease progression allow one to suppose that the three "histological variants" of ETMR may constitute either "polar ends" of a morphologic spectrum or varying differentiation stages of a single tumor entity rather than separate nosologic categories.

In conclusion, we identified uniform molecular signatures occurring in a representative subset of embryonal brain tumors with multilayered rosettes indicating that ETANTR, EBL, and MEPL comprise a single biological entity, which could potentially be designated in future WHO schemes as ETMR. For molecular diagnosis of this tumor category and to distinguish them from other embryonal tumors of the CNS, combined LIN28A IHC and FISH analysis of the $19 \mathrm{q} 13.42$ locus are recommended as routine diagnostic markers. Since misdiagnosis for controversial "poorly differentiated" embryonal CNS neoplasms is not uncommon, all tumors and especially CNS-PNETs harboring combined LIN28 expression and 19q13.42 amplification should be classified as ETMR, even in absence of the key histological patterns. As a next step, it will be important to understand the distinct biological significance of the prototypic molecular events in ETMR which may provide therapeutic targets for novel treatment strategies for these highly aggressive and therapy-resistant pediatric CNS malignances.

Open Access This article is distributed under the terms of the Creative Commons Attribution License which permits any use, distribution, and reproduction in any medium, provided the original author(s) and the source are credited.

\section{References}

1. Adamek D, Sofowora KD, Cwiklinska M, Herman-Sucharska I, Kwiatkowski S (2013) Embryonal tumor with abundant neuropil and true rosettes: an autopsy case-based update and review of the literature. Child Nerv Syst 29(5):849-854

2. Al-Hussaini M, Abuirmeileh N, Swaidan M, Al-Jumaily U, Rajjal H, Musharbash A, Hashem S, Sultan I (2011) Embryonal tumor with abundant neuropil and true rosettes: a report of three cases of a rare tumor, with an unusual case showing rhabdomyoblastic and melanocytic differentiation. Neuropathology 31(6):620-625

3. Behdad A, Perry A (2010) Central nervous system primitive neuroectodermal tumors: a clinicopathologic and genetic study of 33 cases. Brain Pathol 20(2):441-450

4. Buccoliero AM, Castiglione F, Rossi Degl'Innocenti D, Franchi A, Paglierani M, Sanzo M, Cetica V, Giunti L, Sardi I, Genitori L, Taddei GL (2010) Embryonal tumor with abundant neuropil and true rosettes: morphological, immunohistochemical, ultrastructural and molecular study of a case showing features of medulloepithelioma and areas of mesenchymal and epithelial differentiation. Neuropathology 30(1):84-91

5. Ceccom J, Bourdeaut F, Loukh N, Rigau V, Milin S, Takin R, Richer W, Uro-Coste E, Couturier J, Bertozzi AI, Delattre O, Delisle MB (2013) Embryonal tumor with multilayered rosettes: diagnostic tools update and review of the literature. Clin Neuropathol (Epub ahead of print)

6. Eberhart CG, Brat DJ, Cohen KJ, Burger PC (2000) Pediatric neuroblastic brain tumors containing abundant neuropil and true rosettes. Pediatr Dev Pathol 3(4):346-352

7. Fan X, Wang Y, Kratz J, Brat DJ, Robitaille Y, Moghrabi A, Perlman EJ, Dang CV, Burger PC, Eberhart CG (2003) hTERT gene amplification and increased mRNA expression in central nervous system embryonal tumors. Am J Pathol 162(6):1763-1769

8. Ferri Niguez B, Martínez-Lage JF, Almagro MJ, Fuster JL, Serrano C, Torroba MA, Sola J (2010) Embryonal tumor with abundant neuropil and true rosettes (ETANTR): a new distinctive variety of pediatric PNET: a case-based update. Childs Nerv Syst 26(8):1003-1008

9. Friedrich C, von Bueren AO, von Hoff K, Gerber NU, Ottensmeier H, Deinlein F, Benesch M, Kwiecien R, Pietsch T, Warmuth-Metz M, Faldum A, Kuehl J, Kortmann RD, Rutkowski S (2013) Treatment of young children with CNS-primitive neuroectodermal tumors/pineoblastomas in the prospective multicenter trial HIT 2000 using different chemotherapy regimens and radiotherapy. Neuro Oncol 15(2):224-234

10. Fuller C, Fouladi M, Gajjar A, Dalton J, Sanford RA, Helton KJ (2006) Chromosome 17 abnormalities in pediatric neuroblastic tumor with abundant neuropil and true rosettes. Am J Clin Pathol 126(2):277-283

11. Gessi M, Giangaspero F, Lauriola L, Gardiman M, Scheithauer BW, Halliday W, Hawkins C, Rosenblum MK, Burger PC, Eberhart CG (2009) Embryonal tumors with abundant neuropil and true rosettes: a distinctive CNS primitive neuroectodermal tumor. Am J Surg Pathol 33(2):211-217

12. Gessi M, Zur Muehlen A, Lauriola L, Gardiman MP, Giangaspero F, Pietsch T (2011) TP53, $\beta$-Catenin and c-myc/N-myc status in embryonal tumours with ependymoblastic rosettes. Neuropathol Appl Neurobiol 37(4):406-413

13. Hovestadt V, Remke M, Kool M, Pietsch T, Northcott PA, Fischer R, Cavalli FM, Ramaswamy V, Zapatka M, Reifenberger G, Rutkowski S, Schick M, Bewerunge-Hudler M, Korshunov A, Lichter P, Taylor MD, Pfister SM, Jones DT (2013) Robust molecular subgrouping and copy-number profiling of medulloblastoma from small amounts of archival tumour material using high-density DNA methylation arrays. Acta Neuropathol 125(6):913-916

14. Judkins AR, Ellison DW (2010) Ependymoblastoma: dear, damned, distracting diagnosis, farewell! Brain Pathol 120(1):133-139

15. Korshunov A, Remke M, Gessi M, Ryzhova M, Hielscher T, Witt H, Tobias V, Buccoliero AM, Sardi I, Gardiman MP, Bonnin J, Scheithauer B, Kulozik AE, Witt O, Mork S, von Deimling A, Wiestler OD, Giangaspero F, Rosenblum M, Pietsch T, Lichter P, Pfister SM (2010) Focal genomic amplification at 
19q13.42 comprises a powerful diagnostic marker for embryonal tumors with ependymoblastic rosettes. Acta Neuropathol 120(2):253-260

16. Korshunov A, Ryzhova M, Jones DT, Northcott PA, van Sluis P, Volckmann R, Koster J, Versteeg R, Cowdrey C, Perry A, Picard D, Rosenblum M, Giangaspero F, Aronica E, Schüller U, Hasselblatt M, Collins VP, von Deimling A, Lichter P, Huang A, Pfister SM, Kool M (2012) LIN28A immunoreactivity is a potent diagnostic marker of embryonal tumor with multilayered rosettes (ETMR). Acta Neuropathol 124(6):875-881

17. Li M, Lee KF, Lu Y, Clarke I, Shih D, Eberhart C, Collins VP, Van Meter T, Picard D, Zhou L, Boutros PC, Modena P, Liang ML, Scherer SW, Bouffet E, Rutka JT, Pomeroy SL, Lau CC, Taylor MD, Gajjar A, Dirks PB, Hawkins CE, Huang A (2009) Frequent amplification of a chr19q13.41 microRNA polycistron in aggressive primitive neuroectodermal brain tumors. Cancer Cell 16(6):533-546

18. Louis DN, Ohgaki H, Wiestler OD, Cavenee WK (2007) WHO classification of tumors of the central nervous system. IARC press, Lyon

19. Manjila S, Ray A, Hu Y, Cai DX, Cohen ML, Cohen AR (2011) Embryonal tumors with abundant neuropil and true rosettes: 2 illustrative cases and a review of the literature. Neurosurg Focus 30(1):E2

20. Northcott PA, Jones DT, Kool M, Robinson GW, Gilbertson RJ, Cho YJ, Pomeroy SL, Korshunov A, Lichter P, Taylor MD, Pfister SM (2012) Medulloblastomics: the end of the beginning. Nat Rev Cancer 12(12):818-834

21. Nobusawa S, Yokoo H, Hirato J, Kakita A, Takahashi H, Sugino T, Tasaki K, Itoh H, Hatori T, Shimoyama Y, Nakazawa A, Nishizawa S, Kishimoto H, Matsuoka K, Nakayama M, Okura N, Nakazato Y (2012) Analysis of chromosome 19q13.42 amplification in embryonal brain tumors with ependymoblastic multilayered rosettes. Brain Pathol 22(5):689-697

22. Paulus W, Kleihues P (2010) Genetic profiling of CNS tumors extends histological classification. Acta Neuropathol 120(2):269-270

23. Picard D, Miller S, Hawkins CE, Bouffet E, Rogers HA, Chan TS, Kim SK, Ra YS, Fangusaro J, Korshunov A, Toledano H, Nakamura H, Hayden JT, Chan J, Lafay-Cousin L, Hu P, Fan X, Muraszko KM, Pomeroy SL, Lau CC, Ng HK, Jones C, Van
Meter T, Clifford SC, Eberhart C, Gajjar A, Pfister SM, Grundy RG, Huang A (2012) Markers of survival and metastatic potential in childhood CNS primitive neuro-ectodermal brain tumours: an integrative genomic analysis. Lancet Oncol 13(8):838-848

24. Pfister S, Remke M, Castoldi M, Bai AH, Muckenthaler MU, Kulozik A, von Deimling A, Pscherer A, Lichter P, Korshunov A (2009) Novel genomic amplification targeting the microRNA cluster at $19 \mathrm{q} 13.42$ in a pediatric embryonal tumor with abundant neuropil and true rosettes. Acta Neuropathol 117(4):457-464

25. Rickert CH, Hasselblatt M (2006) Cytogenetic features of ependymoblastomas. Acta Neuropathol 111(6):559-562

26. Sturm D, Witt H, Hovestadt V, Khuong-Quang DA, Jones DT, Konermann C, Pfaff E, Tönjes M, Sill M, Bender S, Kool M, Zapatka M, Becker N, Zucknick M, Hielscher T, Liu XY, Fontebasso AM, Ryzhova M, Albrecht S, Jacob K, Wolter M, Ebinger M, Schuhmann MU, van Meter T, Frühwald MC, Hauch H, Pekrun A, Radlwimmer B, Niehues T, von Komorowski G, Dürken M, Kulozik AE, Madden J, Donson A, Foreman NK, Drissi R, Fouladi M, Scheurlen W, von Deimling A, Monoranu C, Roggendorf W, Herold-Mende C, Unterberg A, Kramm CM, Felsberg J, Hartmann C, Wiestler B, Wick W, Milde T, Witt O, Lindroth AM, Schwartzentruber J, Faury D, Fleming A, Zakrzewska M, Liberski PP, Zakrzewski K, Hauser P, Garami M, Klekner A, Bognar L, Morrissy S, Cavalli F, Taylor MD, van Sluis P, Koster J, Versteeg R, Volckmann R, Mikkelsen T, Aldape K, Reifenberger G, Collins VP, Majewski J, Korshunov A, Lichter P, Plass C, Jabado N, Pfister SM (2013) Hotspot mutations in $\mathrm{H} 3 \mathrm{~F} 3 \mathrm{~A}$ and IDH1 define distinct epigenetic and biological subgroups of glioblastoma. Cancer Cell 22(4):425-437

27. Wang Y, Chu SG, Xiong J, Cheng HX, Chen H, Yao XH (2011) Embryonal tumor with abundant neuropil and true rosettes (ETANTR) with a focal amplification at chromosome 19q13.42 locus: further evidence of two new instances in China. Neuropathology 31(6):639-647

28. Woehrer A, Slavc I, Peyrl A, Czech T, Dorfer C, Prayer D, Stary S, Streubel B, Ryzhova M, Korshunov A, Pfister SM, Haberler C (2011) Embryonal tumor with abundant neuropil and true rosettes (ETANTR) with loss of morphological but retained genetic key features during progression. Acta Neuropathol 122(6):787-790 